Published by Al-Nahrain College of Medicine P-ISSN 1681-6579

E-ISSN 2224-4719

Email: iraqijms@colmed-alnahrain.edu.iq

http://www.colmed-alnahrain.edu.iq

http://www.iraqijms.net

Iraqi JMS 2019; Vol. 17(1)

\title{
Multiplex RT-PCR Based Detection of Human Bocavirus and Other Respiratory Viruses in Infants and Young Children with Lower Respiratory Tract Infection
}

\author{
Zaid S. Rasheed ${ }^{1}$ BSC, Arwa M. A. Al-Shuwaikh² PhD, Khaled R. Issa ${ }^{3}$ FICSMS
}

${ }^{1} \mathrm{Al}$-Shaheed Al-Sadr General Hospital, Ministry of Health, ${ }^{2}$ Dept. of Microbiology, College of Medicine, Al-Nahrain University, Baghdad, Iraq, ${ }^{3}$ Dept. of Pediatrics, Ibn Al-Baladi Hospital, Baghdad, Iraq

\begin{abstract}
Background Human Bocavirus ( $\mathrm{hBoV}$ ) has recently been identified as a causative agent of acute respiratory infection (ARI) in infant and young children. However, there is little information about its frequency and importance as a cause of lower respiratory tract infection (LRTI) in Iraq.

Objective

Methods

To assess the frequency of hBoV and co-infection rate in infants and young children with LRTI.

Nasopharyngeal/throat swabs were collected during the peak winter months from 100 hospitalized infants and young children less than 5 years of age with LRTI in Baghdad, Iraq. Five viruses were investigated by Multiplex Real-Time Polymerase Chain Reaction (RT-PCR).

Results It was found that $71(71 \%)$ had a viral infection either single or mixed. Six out of 100 samples $(6 \%)$ were $\mathrm{hBoV}$ positive, $10(10 \%)$ were parainfluenza virus positive, $12(12 \%)$ tested positive for adenovirus, $58(58 \%)$ were rhinovirus positive and none of the samples gave positive results for coronavirus. Sixteen samples showed mixed infection with rhinovirus, eight of these (8\%) with parainfluenza virus, $6(6 \%)$ with adenovirus, and 2 (2\%) with hBoV. There were no significant differences between the viral infected and non-infected patients with respect to age, gender, crowding status, gestational age, diagnosis at presenting and hospital stay (the average stay of viral-infected patients in the hospital was three days). In contrast, exposure to smoking was significantly more associated with viral-infected children than virus-free children ( $80 \%$ vs. $44.83 \%, P<0.001)$. In addition, viral-infected children showed significantly less proportion for need for intensive care unit than virus-free children $(15.5 \%$ vs. $79.31 \%, \mathrm{P}<0.001)$. Breastfeeding was found to have significant adverse association with viral infection $(P<0.001)$. About one-third of viral-infected children had a medical history involving a disease other than respiratory infection $(P<0.001)$. Finally, viral-infected children were reported to have longer period of illness before hospital admission (6.32 \pm 5.49 days) than virus-free children (6.32 \pm 5.49 days vs. $3.38 \pm 2.37$ days, $\mathrm{P}<0.01$ ).

Conclusion More than two third of children with respiratory tract infection have been viral infection either single or mixed. Multiplex RT-PCR has the potential for clinical use in the rapid and differential detection of viral infection.

Keywords Viral respiratory tract infection, Children, Multiplex Real Time PCR

Citation

Rasheed ZS, Al-Shuwaikh AMA, Issa KR. Multiplex RT-PCR based detection of Human Bocavirus and other respiratory viruses in infants and young children with lower respiratory tract infection. Iraqi JMS. 2019; 17(1): 74-82. doi: 10.22578/IJMS.17.1.11
\end{abstract}

List of abbreviations: hBoV = Human bocavirus; hPiv = Human parainfluenza; hRv = Human rhinovirus; hAdv = Human adenovirus; hCov = Human coronavirus, LRTI = Lower respiratory tract infection

\section{Introduction}

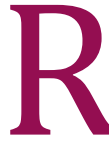
espiratory infections are the leading cause of morbidity and mortality in children worldwide. The World Health
Organization (WHO) ranks respiratory tract infections as the second leading cause of death in children aged less than five years of age, predominantly in developing countries $(1,2)$. Human bocavirus (hBoV) is a ssDNA virus that first discovered in 2005. It has been classified as a member of Parvoviridae family and associated 
with respiratory illness and gastroenteritis in children ${ }^{(3)}$. Currently, four genotypes have been described (hBoV 1 to 4). The hBoV1-2 has been associated with respiratory tract infections, while hBoV2-4 associated with gastrointestinal disease (1). There has been controversy regarding $\mathrm{hBoV}$ as a sole causal pathogen due to the high observation of co-infection with other viruses and the inability to fulfill Koch postulates given the challenges of viral culture ${ }^{(4)}$. In addition, individuals with low viral load are more likely to be co-infected with other pathogens compared to those with high viral load $(57 \%$ vs. $38.9 \%)$. The rate of co-infections in subjects with respiratory infections and hBoV-positivity ranges from $8.3 \%$ to $100 \%{ }^{(5)}$. Other respiratory viruses, human parainfluenza viruses (hPiv 1 to 4 ) are ssRNA viruses belongs to Paramyxoviridae family. It has been associated with a broad spectrum of respiratory tract disease including common cold, croup, bronchitis, bronchiolitis and pneumonia and certain serotype are frequently associated with certain illness ${ }^{(6,7)}$. Human adenoviruses (hAdv) are dsDNA virus, which belongs to Adenoviridae family and classified as seven species (hAdv A to $G)$, acute respiratory infections (ARI) are mainly caused by species $B, C$ and $E$ worldwide. Children with hAdv pneumonia may be misdiagnosed and inadequately treated (8). Human rhinoviruses (hRv) are ssRNA viruses, which belongs to Picornaviridae family. They are divided into three species, ( $\mathrm{hRv} A$ to $\mathrm{C}$ ) and approximately 150 distinct genotypes identified within those species. Although once thought to cause only the common cold, it is now known that $h R v$ are associated with Lower respiratory tract infection (LRTI) including bronchiolitis and pneumonia and can exacerbate asthma in children and adult (9,10). Finally, Human coronaviruses (hCov) are ssRNA viruses that most commonly associated with mild respiratory illnesses, but can cause severe illness, such as severe acute respiratory syndrome (SARS) coronavirus (11). To date, six hCov have been identified of which four (OC43, E229, NL63, and HKUI) are globally circulate in the human population ${ }^{(12)}$. The role of the most common respiratory viruses has been well described, while the roles of other less known, viruses such as hBoV remains largely unknown especially in developing countries ${ }^{(13,14)}$.

This study attempted to determine the frequency of HBoV in infant and young children with lower respiratory tract infection, as well as its potential to cause infection as a sole etiological agent or as co-infection with other viral pathogens and to give real insight to prevalence of viral infections in a sample of Iraqi children.

\section{Methods}

\section{Specimen collection:}

One hundred nasopharyngeal/throat swabs samples were collected during November, 2017 to March, 2018 from hospitalized infants and young children with LRTI at Ibn Al-Baladi Teaching Hospital, Medical City Hospital and AlImamein Al-Kadhimein Medical City in Baghdad, Iraq. Children age range was 1 month to 60 months, they were enrolled in this study after an informed consent was obtained from parents and approved from Institutional Review Boards of College of Medicine, Al-Nahrain University (approval no. M.M.M./22 in 27/12/2017).

Nasopharyngeal/throat swabs were taken using flocked swab regular (catalog number 80346C, Copan Diagnostic, Italy) and flocked swab nasopharyngeal (catalog number 80503CS, Copan Diagnostic, Italy) and then combined into a single tube of viral universal transport medium (3 ml UTM, Copan Diagnostic, Italy). Specimens were transported in cold packs to the laboratory within 8 hours of collection and preserved frozen at $\left(-70{ }^{\circ} \mathrm{C}\right)$ until tested. Questionnaire form was used to collect information of clinical symptoms before admission to the hospital and demographic information by parental interview. Medical files were reviewed for selected clinical data of the patients, only patients with LRTI were included. The crowding index was calculated according to the American crowding index ${ }^{(15)}$.

\section{RNA and DNA extraction}


RNA/DNA were extracted from frozen specimen aliquots according to manufacturer's instructions using Ribo-Sorb RNA/DNA Extraction kit (Sacace Biotec, Italy). Internal Control (IC) was used in the isolation procedure which serves as an amplification control for each individually processed specimen and to identify possible reaction inhibition. The concentration and purity of RNA/DNA extracts were measured by a nanodrop (BioDrop $\mu$ LITE, BioDrop Co., UK). The isolated RNA/DNA was stored frozen at $\left(-70^{\circ} \mathrm{C}\right)$ until analysis.

\section{Multiplex RT-PCR}

RNA was reverse transcribed to cDNA, which used as a template for Multiples RT-PCR. Reactions mix were prepared according to the manufacturer's instructions using ARVI Screen Real-TM kit (Sacace, Itaily). Real-time PCR was performed with the Magnetic Induction Cycler (Mic, Australia) using primers and probe sequences that amplified a fragment encompassing specific region to each virus, allowing detection of five viruses hBov, hPiv (14), hAdv (B, C, E), hRv and hCov (OC43, E229, NL63, and HKUI). Positive and negative controls were included to verify the validation of the reaction. Instrument setting according to manufacture instruction for roter type instruments. The real-time thermal condition included holding step at 1 cycle at $95{ }^{\circ} \mathrm{C}$ for 15 min (as an initial denaturation), cycling step including 10 cycles of $95^{\circ} \mathrm{C}$ for $10 \mathrm{sec}, 54{ }^{\circ} \mathrm{C}$ for $25 \mathrm{sec}$ and $72{ }^{\circ} \mathrm{C}$ for $25 \mathrm{sec}$, and 35 cycles of 95 ${ }^{\circ} \mathrm{C}$ for $10 \mathrm{sec}, 54{ }^{\circ} \mathrm{C}$ for $25 \mathrm{sec}$ and $72{ }^{\circ} \mathrm{C}$ for 25 sec with fluorescence data collected during the $54{ }^{\circ} \mathrm{C}$ annealing/extension step. Fluorescence is detected is in FAM/Green, JOE/Yellow/HEX/Cy3 and ROX/Orange/TexasRed fluorescent channels. The results were interpreted by the software of Real Time PCR instrument by the crossing (or not crossing) of the fluorescence curve with the threshold line. The sensitivity of detection with this method is approaching 100 copies/reaction in respiratory specimens according to manufacturer.

\section{Statistical analysis}

Data were analyzed using SPSS version 22.0 (Chicago, IL, USA). Descriptive statistic mean \pm S.D. and frequency were calculated, Comparisons of demographic and clinical data between groups were made using Chi-square $(x 2)$ test for categorical variables and student $t$ test for mean differences. A P value $<0.05$ was taken as threshold of statistical significance.

\section{Results}

\section{Patients and sample inclusion}

This study included 100 infants and young children with LRTI. The age range of study population was ( 1 to 60 ) months. Sixty percent of the them were male while female represented $40 \%$. Most children (82\%) were mature; however, $24 \%$ of them needed an intensive care unit for sometimes. Over half (58\%) did not have breastfeeding compared with only $22 \%$ having bottle feeding and $20 \%$ with mixed feeding. In addition, 70\% were exposed to smokers. Fifty-two of children were found to live in severely crowded conditions. Approximately two-third of children were present with pneumonia with or without bronchitis. The majority of children (82\%) had a hospital stay for less than 3 days, and about half of them had a medical history especially jaundice (14\%) and pneumonia (6\%) as shown in table (1). 
Table 1. Perinatal and clinical characteristics of 100 infant and young children included in this study

\begin{tabular}{|c|c|c|}
\hline \multicolumn{2}{|c|}{ Variables } & \multirow{2}{*}{$\begin{array}{c}\text { No. (\%) } \\
60(60 \%)\end{array}$} \\
\hline Arocrouns /monthel & $1-6$ & \\
\hline Age groups (montns) & $7-12$ & $26(26 \%)$ \\
\hline & $13-60$ & $14(14 \%)$ \\
\hline \multirow{2}{*}{ Gender } & Female & $40(40 \%)$ \\
\hline & Male & $60(60 \%)$ \\
\hline \multirow{2}{*}{ Exposure to smoking } & Exposed & $70(70 \%)$ \\
\hline & Not exposed & $30(30 \%)$ \\
\hline \multirow{3}{*}{ Crowding index } & Severely crowded & $52(52 \%)$ \\
\hline & Crowded & $26(26 \%)$ \\
\hline & Not crowded & $22(22 \%)$ \\
\hline \multirow{2}{*}{ Gestational age } & Premature & $18(18 \%)$ \\
\hline & Mature & $82(82 \%)$ \\
\hline \multirow{2}{*}{ History of Neonatal ICU } & Yes & $24(24 \%)$ \\
\hline & No & $76(76 \%)$ \\
\hline \multirow{3}{*}{ Breastfeeding } & Yes & $22(22 \%)$ \\
\hline & No & $58(58 \%)$ \\
\hline & Mix & $20(20 \%)$ \\
\hline \multirow{3}{*}{ No. days prior to admission } & $\leq 3$ days & $47(47 \%)$ \\
\hline & 4-14 days & 45 (45\%) \\
\hline & $>14$ days & $8(8 \%)$ \\
\hline \multirow{4}{*}{ Diagnosis } & Pneumonia & $62(62 \%)$ \\
\hline & Bronchitis & $24(24 \%)$ \\
\hline & Bronchiolitis & $10(10 \%)$ \\
\hline & Asthma & $4(4 \%)$ \\
\hline \multirow{2}{*}{ Length of hospital stay } & 1-3 days & $82(82 \%)$ \\
\hline & $>3$ days & $18(18 \%)$ \\
\hline \multirow{11}{*}{ Medical history } & None & $52(52 \%)$ \\
\hline & Pneumonia & $6(6 \%)$ \\
\hline & Seizure & $2(2 \%)$ \\
\hline & Sepsis & $4(4 \%)$ \\
\hline & Cardiac septal defect & $2(2 \%)$ \\
\hline & Meningitis & $2(2 \%)$ \\
\hline & Cough & $2(2 \%)$ \\
\hline & Cystitis & $2(2 \%)$ \\
\hline & Hernia & $8(8 \%)$ \\
\hline & Jaundice & $14(14 \%)$ \\
\hline & Mixed & $6(6 \%)$ \\
\hline
\end{tabular}

\section{Viral infection and co-infection}

In total 100 patients, 71 (71\%) were found to have a viral infection either single or mixed. Primarily, the study targeted five viruses; however, only four were detected. These were hBov, hPiv, hAdv and hRv which represented $6 \%, 10 \%, 12 \%$ and $58 \%$, respectively (Figure 1 ). On the other hand, none of the samples gave 
positive results for hCov. All mixed infections were found to be a combination of two viruses one of them hRv. Eight of these (8\%) with hPiv,
$6(6 \%)$ with hAdv, and 2 (2\%) with hBov (Figure 2).

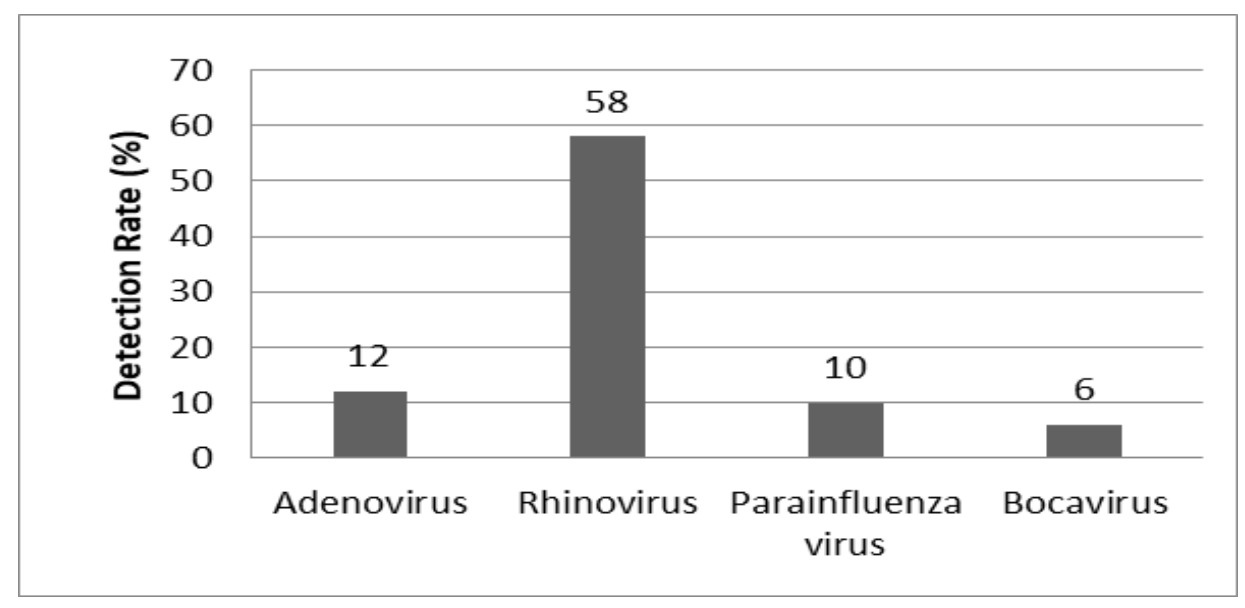

Figure 1. The prevalence of respiratory viruses during the studied period

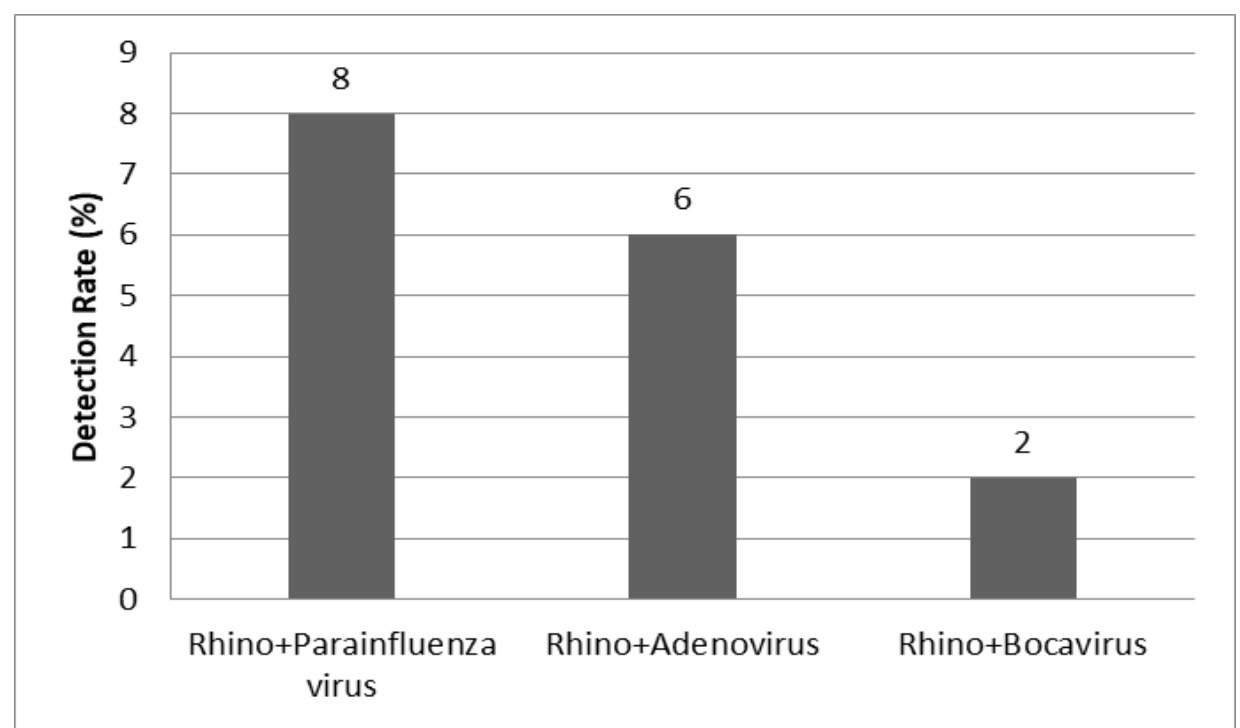

Figure 2. The prevalence of co-infection during the studied period

\section{Demographic and clinical characteristics}

Overall, 71 children were found to have viral (one or two) infection versus 29 children without such infection (may have other viruses or other microoganisms). Each of age of the child, gender, crowding status, gestational age, diagnosis at presenting and hospital stay did not have a significant association with viral infection. On the other hand, five characteristics associated in some way significantly with the viral infection as shown in table (2).

More than $80 \%$ of viral-infected children were reported to be exposed for smoking versus $44.8 \%$ of virus-free children $(P<0.001)$. In contrast, viral-infected children showed significantly less proportion for need for intensive care unit (ICU) than virus-free children (15.5\% vs. $79.31 \%, \mathrm{P}<0.001)$. Breastfeeding was 
found to have significant adverse association with viral infection, since a high proportion of virus-free children (41.38\%) had breast feeding ( $P=0.004)$.

About one-third of viral-infected children had had a medical history involving a disease other than respiratory infection such as jaundice and sepsis compared with only $10.34 \%$ in virus-free children $(P=0.003)$. Finally, viral-infected children were reported to have longer period of illness before hospital admission (6.32 \pm 5.49 days) than virus-free children (3.38 \pm 2.37 days) $(P=0.02)$. Also, viral-infected children were more likely to stay an extra day in the hospital (3 vs. 2 days, 0.082), although it not reached statistical significance (Table 2).

Table 2. Association of demographic and clinical characteristic with general viral infection

\begin{tabular}{|c|c|c|c|}
\hline Variables & $\begin{array}{c}\text { Viral detected } \\
71 \\
\end{array}$ & $\begin{array}{c}\text { No Virus detected } \\
29\end{array}$ & P-value \\
\hline Age per months (mean $\pm S D$ ) & $9.49 \pm 8.86$ & $14.34 \pm 12.2$ & 0.411 \\
\hline \multicolumn{4}{|l|}{ Gender, No. (\%) } \\
\hline Male & $44(61.97 \%)$ & $16(\%)$ & \multirow{2}{*}{0.53} \\
\hline Female & $27(38 \%)$ & $13(\%)$ & \\
\hline \multicolumn{4}{|l|}{ Exposure to smoking, No. (\%) } \\
\hline No & $14(19.72 \%)$ & $16(55.17 \%)$ & \multirow{2}{*}{$<0.001$} \\
\hline Yes & $57(80.28 \%)$ & $13(44.83 \%)$ & \\
\hline \multicolumn{4}{|l|}{ Crowding, No. (\%) } \\
\hline Not crowded & $13(18.31 \%)$ & $9(31 \%)$ & \multirow{2}{*}{0.173} \\
\hline Crowded & $58(81.69 \%)$ & $20(69 \%)$ & \\
\hline \multicolumn{4}{|l|}{ Gestational age, No. (\%) } \\
\hline Mature & $57(80.28 \%)$ & $25(86.2 \%)$ & \multirow{2}{*}{0.457} \\
\hline Premature & $14(19.72 \%)$ & $4(13.79 \%)$ & \\
\hline \multicolumn{4}{|l|}{ History of neonatal ICU, No. (\%) } \\
\hline No & $60(84.5 \%)$ & $6(20.69 \%)$ & \multirow{2}{*}{$<0.001$} \\
\hline Yes & $11(15.5 \%)$ & $23(79.31 \%)$ & \\
\hline \multicolumn{4}{|l|}{ Breastfeeding, No. (\%) } \\
\hline No & $45(63.38 \%)$ & $13(44.83 \%)$ & 0.089 \\
\hline Yes & $10(14.08 \%)$ & 12 (41.38\%) & 0.004 \\
\hline Mixed & $16(22.54 \%)$ & $4(13.79 \%)$ & 0.308 \\
\hline \multicolumn{4}{|l|}{ Diagnosis, No. (\%) } \\
\hline Pneumonia & $45(63.38 \%)$ & $17(58.62 \%)$ & 0.657 \\
\hline Bronchitis and bronchiolitis & $31(43.66 \%)$ & $11(37.93 \%)$ & 0.597 \\
\hline Wheezing and asthma & $12(16.9 \%)$ & $6(20.69 \%)$ & 0.658 \\
\hline \multicolumn{4}{|l|}{ Medical history, No. (\%) } \\
\hline No & $37(52.11 \%)$ & $25(86.21 \%)$ & 0.001 \\
\hline Respiratory infection & $7(9.86 \%)$ & $1(3.45 \%)$ & 0.248 \\
\hline Others & $27(30.03 \%)$ & $3(10.34 \%)$ & 0.003 \\
\hline $\begin{array}{l}\text { No. days prior to admission } \\
(\text { mean } \pm S D)\end{array}$ & $6.32 \pm 5.49$ & $3.38 \pm 2.37$ & 0.020 \\
\hline Hospital stay per days (mean \pm SD) & $3.37 \pm 2.73$ & $2.35 \pm 2.09$ & 0.082 \\
\hline
\end{tabular}




\section{Discussion}

In this study, Multiplex RT-PCR allows detection of five viruses at the same time. However, some respiratory viruses were escaped the detection because they not included within the ARVI Screen Real-TM kit. The current study showed that the frequency of hBoV, hPiv, hAdv, hRv and hCov were $6 \%, 10 \%, 12 \%, 58 \%$ and $0 \%$, respectively. This result in consistent with other studies reported that the prevalence of human bocavirus infection in children aged three years and younger is (2.3-5.7\%), which suggests that $\mathrm{hBoV}$ is an uncommon cause of respiratory illness (16-18).

Previous study found that a high rate of hBov coinfections with other viral respiratory pathogens, such as hRv and hAdv. Co-infections have been found in up to $83 \%$ of respiratory samples ${ }^{(5)}$. In this study, only 2 out of 6 hBovinfected children were co-infected with $\mathrm{hRv}$, so it is difficult to confirm the role of hBov as a sole etiological agent due to a small sample size. Jula et al. in 2013 suggested that other respiratory viruses might reactivate hBov from latency, as has been seen with several other DNA viruses, or that they alter the intranasopharyngeal environment and release persisting hBov ${ }^{(19)}$. In contrast, Moesker et al. in 2015 found that (14\%) of cases with severe ARI admitted to ICU showed single hBov-infected which provides strong support that hBov can cause severe ARI in children in the absence of other viral or bacterial co-infections ${ }^{(1)}$. In addition, some studies indicated that a single recent $\mathrm{hBoV}$ infection is associated with a higher viral load than in combination with other viruses ${ }^{(1,20-22)}$.

A study done in Mexico showed that (81.6\%) of young children were positive for viral infected, which support current study in the total percentage of viral infection but slightly differ in the percentage of each virus such as hBov was found in (0.4\%), hPiv in (5.5\%), hAdv in (2.2\%) and hRv in $(16.6 \%)^{(23)}$. Another study conducted in Korea for detection of 11 respiratory viruses showed that viral infection was identified in (60.6\%) of patients, which hPiv-3 was detected in (6.2\%) while hPiv-1 and hCov-NL63 in (1.6\%) (24). This difference in prevalence of specific virus infection may be due to the difference in the time period for sample collection, size of samples, diverse geographical climate, activity of the virus pandemic in the community, testing techniques used and the viral pattern studied (25).

Human Adv infections in current study were comparable to that documented in Jordan $(11.5 \%)$ of hospitalized children less than two years of age and within the range (0.8-27.3\%) reported in other countries (26). In addition, Miller et al. in 2009 detected hRv in (33\%) of hospitalized children with respiratory symptoms and/or fever ${ }^{(10)}$, while Kaplan et al. (2008) identified hRv only in (11\%) of hospitalized young children in Jordan (27). The viruses most frequently co-detected with $h R v$ in ARI samples were hAdv, hPiv, and respiratory syncytial virus (RSV), (12.6\%, 7.2\% and 5.3\%, respectively) (5). Current study showed that 6 out of 12 Adv-infected children were coinfected with hRv. It was reported that the presence of $h R v$ increases the risk for disease severity in acute bronchiolitis by approximately 5 -fold ${ }^{(28)}$.

Our data showed a significant difference in clinical characteristics between viral-infected and viral-free children in regards to exposure to smoking in households $(80.28 \%$ vs. $44.83 \%$, respectively) $(\mathrm{P}<0.001) \quad($ Table 2$)$. It was hypothesized that cigarette smoke exposure increases epithelial susceptibility to some viral infection by increasing the abundance of their receptor ${ }^{(29)}$. Cigarette smoke is a major risk factor increasing the morbidity and mortality rates of viral infection and activating latent infection (26). In addition, a significant difference between viral-infected and viral-free children with respect to breastfeeding was found. Breastfeeding showed to have a protective effect; children who were breastfed for less than one month had 7 times less risk for being hospitalized for acute bronchiolitis in the first three months of life ${ }^{(30)}$. The sensitized T cells or antigen on macrophages in colostrums or milk may transfer to infants and stimulation immune response. Also, breast milk suppresses IgE response which may be important in the pathogenesis of bronchiolitis ${ }^{(31)}$.

Viral-infected children were found to have less history of requirement to intensive care unit admission and mechanical ventilation and 
longer period of illness before hospital admission. This could explain by the fact that some patients with prior hospitalization seeking medical assistance earlier in their illness or, more probably, to the decision to refer patients to hospital being influenced by a history of hospitalization, another factors such: underlying medical condition, home environment and maternal care can play a role (32).

In conclusion, this study has demonstrated the frequency of five respiratory viruses throughout four winter months therefore we may have underestimated the true frequency of some detected viruses due to seasonal variations. Further study with larger sample size and out spreads over multiple seasons is required to understand the epidemiology of respiratory viruses. This study might encourage viruses consideration in respiratory infection diagnosis in children to avoid inappropriate antibiotic therapies.

\section{Acknowledgments}

The authors thank the resident physicians at Ibn Al-Baladi Teaching Hospital, Medical City Hospital and Al-Imamein Al-Kadhimein Medical City for their help in samples collection. This work was supported by L'Oreal-UNESCO for Women in Science Levant and Egypt.

\section{Author contribution}

Dr. Al-Shuwaikh and Rasheed are co-first authors and equally contributed to this paper. Dr. Al-Shuwaikh designed and wrote this manuscript. Rasheed performed all the laboratory work and statistical analysis. Dr. Issa was involved in the patient's management and helped in specimen's collection. All the authors have read and approved the final version of this manuscript.

\section{Conflict of interest}

The authors declare no conflicts of interests for this article.

\section{Funding}

Dr. Arwa M. A. Al-Shuwaikh is supported by L'Oreal-UNESCO for Women in Science Levant and Egypt 2017.

\section{References}

1. Moesker FM, van Kampen JJA, van der Eijk AA, et al. Human bocavirus infection as a cause of severe acute respiratory tract infection in children. Clin Microbiol Infect. 2015; 21(10): 964.e1-964.e8. doi: https://doi.org/10.1016/j.cmi.2015.06.014

2. Kaplan NM, Dove W, Abu-Zeid AF, et al. Human Bocavirus Infection among Children, Jordan. Emerging Infectious Diseases. 2006; 12(9). 1418-20. DOI: 10.3201/eid1209.060417.

3. Gu K, Van Caeseele P, Dust K, et al. Atypical pneumonia due to human bocavirus in an immunocompromised patient. CMAJ. 2017; 189(19): E697-E699. doi: 10.1503/cmaj.161134.

4. Broccolo F, Falcone V, Esposito $S$, et al. Human bocaviruses: possible etiologic role in respiratory infection. J Clin Virol. 2015; 72: 75-81. doi: 10.1016/j.jcv.2015.09.008.

5. Guido M, Tumolo MR, Verri T, et al. Human bocavirus: Current knowledge and future challenges. World J Gastroenterol. 2016; 22(39): 8684-97. doi: 10.3748/wjg.v22.i39.8684.

6. Schomacker H, Schaap-Nutt A, Collins PL, et al. Pathogenesis of acute respiratory illness caused by human parainfluenza viruses. Curr Opin Virol. 2012; 2(3): 294-9. doi: 10.1016/j.coviro.2012.02.001.

7. Yea $C$, Cheung $R$, Collins $C$, et al. The complete sequence of a human parainfluenzavirus 4 genome. Viruses. 2009; 1(1): 26-41. doi: 10.3390/v1010026.

8. Qiu $F-Z$, Shen $X-X$, Zhao $M-C$, et al. A triplex quantitative real-time $P C R$ assay for differential detection of human adenovirus serotypes 2, 3 and 7 . Virol J. 2018; 15(1): 81. doi: 10.1186/s12985-0180983-x.

9. Howard LM, Johnson M, Gil Al, et al. Molecular Epidemiology of Rhinovirus Detections in Young Children. Open Forum Infect Dis. 2016; 3(1): ofw001. doi: 10.1093/ofid/ofw001.

10. Miller EK, Najwa K-B, Williams JV, et al. Human rhinovirus $C$ associated with wheezing in hospitalised children in the Middle East. J Clin Virol. 2009; 46(1): 85-9. doi: 10.1016/j.jcv.2009.06.007.

11. Khuri-Bulos N, Payne DC, Lu X, et al. Middle East respiratory syndrome coronavirus not detected in children hospitalized with acute respiratory illness in Amman, Jordan. Clin Microbiol Infect. 2014; 20(7): 678-82. doi: 10.1111/1469-0691.12438.

12. van der Hoek L. Human coronaviruses: what do they cause? Antivir Ther. 2007; 12(4 Pt B): 651-8.

13. Ali SA, Williams JW, Chen $Q$, et al. Human metapneumovirus in hospitalized children in Amman, Jordan. J Med Virol. 2010; 82(6): 1012-6. doi: 10.1002/jmv.21768.

14. Endo R, Ishiguro N, Kikuta $H$, et al. Seroepidemiology of human Bocavirus in Hokkaido Prefecture, Japan. J Clin Microbiol. 2007; 45(10): 3218-23. doi: 10.1128/JCM.02140-06. 
15. Goodyear RK, Fabian A, Hay J. Finding the crowding index that works best for New Zealand (Statistics New Zealand Working Paper No 11-04). 2011. Available from www.stats.govt.nz.

16. Principi N, Piralla A, Zampiero A, et al. Bocavirus infection in otherwise healthy children with respiratory disease. PLoS One. 2015; 10(8): e0135640. doi: 10.1371/journal.pone.0135640.

17. Chow BD, Huang YT, Esper FP. Evidence of human bocavirus circulating in children and adults, Cleveland, Ohio. J Clin Virol. 2008; 43(3): 302-6. doi: 10.1016/j.jcv.2008.07.009.

18. Bastien N, Chui N, Robinson JL, et al. Detection of human bocavirus in Canadian children in a 1-year study. J Clin Microbiol. 2007; 45(2): 610-3. doi: 10.1128/JCM.01044-06.

19. Jula A, Waris $M$, Kantola $K$, et al. Primary and secondary human bocavirus 1 infections in a family, Finland. Emerg Infect Dis. 2013; 19(8): 1328-31. doi: 10.3201/eid.1908.130074.

20. Ricart S, Garcia-Garcia JJ, Anton A, et al. Analysis of human metapneumovirus and human bocavirus viral load. Pediatr Infect Dis J. 2013; 32(9): 1032-4. doi: 10.1097/INF.0b013e3182932f4f.

21. Zhao B, Yu X, Wang $C$, et al. High human bocavirus viral load is associated with disease severity in children under five years of age. PLoS One. 2013; 8(4): e62318. doi: $10.1371 /$ journal.pone.0062318.

22. Uršič $T$, Jevšnik $M$, Zigon $N$, et al. Human bocavirus and other respiratory viral infections in a 2-year cohort of hospitalized children. J Med Virol. 2012; 84(1): 99-108. doi: 10.1002/jmv.22217.

23. Wong-Chew RM, Garcia-Leon ML, Noyola DE, et al. Respiratory viruses detected in Mexican children younger than 5 years old with community-acquired pneumonia: a national multicenter study. Int J Infect Dis. 2017; 62: 32-8. doi: 10.1016/j.ijid.2017.06.020.

24. Choi EH, Lee HJ, Kim SJ, et al. The Association of Newly Identified Respiratory Viruses with Lower Respiratory Tract Infections in Korean Children, 2000-2005. Clin Infect Dis. 2006; 43(5): 585-92. doi: 10.1086/506350.

25. Zhan $Y$, Yang Z, Chen $R$, et al. Respiratory virus is a real pathogen in immunocompetent community-acquired pneumonia: comparing to influenza like illness and volunteer controls. BMC Pulm Med. 2014; 14: 144. doi: 10.1186/1471-2466-14-144.
26. Al-Toum R, Bdour S, Ayyash H. Adenovirus infections in Jordanian hospitalized pediatric patients: prevalence and clinical features. Jordan Med J. 2009; 43 (3): 171-9.

27. Kaplan NM, Dove W, Abd-Eldayem SA, et al. Molecular epidemiology and disease severity of respiratory syncytial virus in relation to other potential pathogens in children hospitalized with acute respiratory infection in Jordan. J Med Virol. 2008; 80(1): 168-74. doi: 10.1002/jmv.21067.

28. Papadopoulos NG, Moustaki M, Tsolia M, et al. Association of rhinovirus infection with increased disease severity in acute bronchiolitis. Am J Respir Crit Care Med. 2002; 165(9): 1285-9. doi: 10.1164/rccm.200112-118BC.

29. Sharma $P$, Kolawole AO, Core SB, et al. Sidestream smoke exposure increases the susceptibility of airway epithelia to adenoviral infection. PLoS One. 2012; 7(11): e49930. doi: 10.1371/journal.pone.0049930.

30. Albernaz EP, Menezes AMB, Cesar JA, et al. [Risk factors associated with hospitalization for bronchiolitis in the post-neonatal period]. Rev Saude Publica. 2003; 37(4): 485-93.

31. Kumar SG, Majumdar A, Kumar V, et al. Prevalence of acute respiratory infection among under-five children in urban and rural areas of puducherry, India. J Nat Sci Biol Med. 2015; 6(1): 3-6. http://dx.doi.org/10.4103/0976-9668.149069.

32. Meyer-Rath G, Brennan AT, Fox MP, et al. Rates and cost of hospitalisation before and after initiation of antiretroviral therapy in urban and rural settings in South Africa. J Acquir Immune Defic Syndr. 2013; 62(3): 322-8. doi: 10.1097/QAI.0b013e31827e8785.

\footnotetext{
Correspondence to

Dr. Arwa M. A. Al-Shuwaikh

E-mail:

arwa.mujahid@colmed-alnahrain.edu.iq

arwa_alshwaikh_2004@yahoo.com

Received Nov. $7^{\text {th }} 2018$

Accepted Jan. $7^{\text {th }} 2019$
} 